\title{
Expression of the Putative Vesicular Acetylcholine Transporter in Rat Brain and Localization in Cholinergic Synaptic Vesicles
}

\author{
Michelle L. Gilmor, ${ }^{1}$ Norman R. Nash, ${ }^{2}$ Ali Roghani,, ${ }^{3}$ Robert H. Edwards, ${ }^{4}$ Hong Yi,, Steven M. Hersch, ${ }^{2}$ and \\ Allan I. Levey² \\ ${ }^{1}$ Graduate Program in Neuroscience, Division of Biological and Biomedical Sciences, Emory University, \\ Atlanta, Georgia 30322, 2Emory University School of Medicine, Department of Neurology, Atlanta, Georgia 30322, \\ 3Texas Tech University Health Science Center, Department of Pharmacology, Lubbock, Texas 74930, \\ 4 University of California, San Francisco, Department of Neurology, San Francisco, California 94143
}

\begin{abstract}
A cholinergic locus has recently been identified consisting of a unique mammalian genomic arrangement containing the genes for choline acetyltransferase (ChAT) and a putative vesicular acetylcholine transporter (NAChT). Although transcripts for ChAT and VAChT protein have been localized in cholinergic neurons, little is known about the encoded VAChT protein. Here we describe production of highly specific rabbit polyclonal antibodies, generated using a VAChT C-terminus/glutathione$S$-transferase fusion protein, and immunological characterization of the native VAChT protein. These antibodies specifically recognized full-length recombinant VAChT expressed in transfected HeLa cells by Western blotting, with the prominent immunoreactive band at $55 \mathrm{kDa}$. In rat brain homogenates, a single VAChT-immunoreactive band of $\sim 70 \mathrm{kDa}$ was predominant in known areas of cholinergic innervation, including striatum, cortex, hippocampus, and amygdala. Light microscopic
\end{abstract}

immunocytochemistry revealed reaction product in cholinergic cell groups but not in noncholinergic areas. More significantly, immunoreactivity was also concentrated in axonal fibers in many regions known to receive prominent cholinergic innervation, such as cerebral cortex, hippocampus, amygdala, striatum, several thalamic nuclei, and brainstem regions. Electron microscopy using immunoperoxidase revealed that VAChT was localized in axon terminals, and using more precise immunogold techniques, to synaptic vesicles. In VAChT-positive perikarya, the immunogold particles were localized to the cytoplasmic face of the Golgi complex. These findings confirm that VAChT protein is expressed uniquely in cholinergic neurons, concentrated in synaptic vesicles, and at least for the $\mathrm{C}$ terminus, topologically oriented as predicted by models.

Key words: vesicular acetylcholine transporter; cholinergic; presynaptic; synaptic vesicles; antibodies; transporters
Cholinergic neurotransmission in the CNS is dependent on three proteins that are believed to define cholinergic neurons uniquely: choline acetyltransferase (ChAT), the enzyme that synthesizes acetylcholine; high-affinity choline transporter (HAChT), the sodium-dependent plasma membrane transporter that recycles choline formed from the breakdown of acetylcholine in the synaptic cleft by acetylcholinesterase; and vesicular acetylcholine transporter (VAChT), the proton-dependent transporter that packages acetylcholine synthesized in the cytoplasm into synaptic vesicles. To date, ChAT has been the most widely studied and has revealed the prominent role of cholinergic transmission in Alzheimer's disease and other nervous system disorders (Coyle et al., 1983).

Recent cloning of the putative VAChT gene revealed that a single genetic locus encodes both ChAT and VAChT, providing a unique genetic mechanism for governing the cholinergic phenotype of neurons (Alfonso et al., 1993; Bejanin et al., 1994; Erickson et al., 1994; Roghani et al., 1994). Hydropathy analysis of the VAChT-predicted amino acid sequence suggests a protein with 12 transmembrane domains, with the $\mathrm{N}$ and $\mathrm{C}$ termini in the cyto-

\footnotetext{
Received Oct. 27, 1995; revised Jan. 11, 1996; accepted Jan. 17, 1996.

This work was supported by the Alzhcimer's Disease and Related Disorders Association (IIRG-95-172). We thank D. Rye, C. Heilman, H. Rees, S. Counts, Y. Qian, E. Barker, and T. Steininger for technical assistance and helpful discussions.

Correspondence should be addressed to Allan I. Levey, Department of Neurology, Emory University School of Medicine, Woodruff Memorial Research Building, Suite 6000, Atlanta, GA 30322.

Copyright 1996 Society for Neuroscience $0270-6474 / 96 / 162179-12 \$ 05.00 / 0$
}

plasm, and a large intravesicular loop between transmembrane domains I and II. Sequence homology places VAChT into a family of transporter proteins that includes two vesicular monoamine transporters (VMATs). These vesicular transporters are believed to concentrate neurotransmitters in synaptic vesicles through exchange of protons for neurotransmitter; however, attempts to determine the kinetic parameters of acetylcholine transport have been unsuccessful because of low transport levels in heterologous expression systems (Erickson et al., 1994). Additionally, the localization of the VAChT protein to synaptic vesicles remains unproven. In rats and humans, the coding sequence for VAChT is contained completely within the first intron of the ChAT gene. Moreover, mRNAs isolated from rat spinal cord have shown that some transcripts of VAChT and ChAT share a $5^{\prime}$ untranslated exon (Bejanin et al., 1994; Cervini et al., 1995). This is similar to the arrangement observed in Caenorhabditis elegans (Alfonso et al., 1994). In situ hybridization studies suggest that expression patterns of VAChT and ChAT mRNAs are coupled tightly in the CNS, possibly because of shared genetic regulatory elements (Schafer et al., 1994). ${ }^{3} \mathrm{H}$-vesamicol binding autoradiography in Alzheimer's disease tissue, however, suggests that this regulation may be uncoupled in disease states, because levels of VAChT binding are unchanged or increased despite the marked reductions in ChAT (Kish et al., 1990; Ruberg et al., 1990). Further understanding of the regulation, subcellular targeting, and topology of the putative VAChT molecule demands new approaches for study at the protein level. 
The purpose of the present study was to produce selective polyclonal antibodies to the VAChT and to characterize the native protein in brain. Rabbit polyclonal antifusion protein antibodies directed against the $\mathrm{C}$ terminus were developed, and specificity was established by immunoblotting. The antibodies were then used to identify VAChT protein in rat brain, establishing its expression uniquely in cholinergic neurons, and to confirm its localization in synaptic vesicles. Moreover, the cytoplasmic localization of the $\mathrm{C}$ terminus is consistent with models of VAChT protein topology.

\section{MATERIALS AND METHODS}

$V A C h T-p G E X-2 T$ plasmid construction and expression. A fusion protein incorporating the putative $\mathrm{C}$ terminus (Ct; amino acids 478-530) of the rat VAChT (Roghani et al., 1994) was produced with the pGEX-2T bacterial expression system (Smith and Johnson, 1988). The cDNA encoding the carboxyl terminus was subcloned using PCR (Perkin-Elmer Cetus, Norwalk, CT) to amplify the region between nucleotides 2290 and 2452 of the cloned rat VAChT. To facilitate successful subcloning and correct fragment orientation, primers were designed (5'-TTAATT $G$ GATCCTCGCGTTCGGAGCGCGATGTG and 5'-TTAATTGAATTCGCTAGCTGCGGGAGTAATAGTT) with either of two restriction sites (Bam HI or Eco RI), introduced into forward and reverse primers, respectively (marked by italics in above sequences). Full-length rat VAChT cDNA was used as template for PCR reactions. Amplified DNA segments were purified and subcloned between the BamHI and EcoRI sites of pGEX-2T. Recombinants were sequenced by the dideoxynucleotide chain-termination method using Sequenase version 2.0 (United States Biochemical, Cleveland, $\mathrm{OH}$ ) and 7-deaza-dGTP.

The encoded fusion protein contains a $27 \mathrm{kDa}$ fragment of helminthic glutathione- $S$-transferase (GST) fused at the $C$ terminus with the rat VAChT C terminus. The fusion protein was expressed in Escherichia coli [BL21 (DE3) strain] cells transformed with the pGEX-2T plasmids. Cells were grown to an $\mathrm{OD}_{595}$ of 0.4 and were pelleted after 3-4 hr of induction by isopropylthiogalactoside. Pre- and postinduction culture samples were analyzed by SDS-PAGE to reveal intense de novo protein bands. The induced bacteria were lysed by incubation with lysozyme and repeated freezing and thawing. The soluble fusion protein was affinity-purified from the bacterial lysates against immobilized glutathione conjugated to epoxy-activated agarose (Sigma, St. Louis, MO) and eluted with excess free reduced glutathione. Purified fusion protein preparations were verified by SDS-PAGE analysis. Fusion proteins were also made containing the $\mathrm{N}$ terminus (amino acids $1-33$ ) and the intravesicular loop (amino acids 61-121); however, these proteins did not produce useful antibodies or were insoluble and thus are not discussed further.

Antibody production. A New Zealand white rabbit was immunized for polyclonal antibody production with the $\mathrm{Ct}$-fusion protein. The animal received a primary injection of $500 \mu \mathrm{g} \mathrm{Ct}$-fusion protein emulsified in complete Freund's adjuvant and subsequent monthly boost injections of $\sim 200 \mu \mathrm{g}$ of Ct-fusion protein emulsified in incomplete Freund's adjuvant. Bleeds were obtained at 3 and 4 weeks postboost, clotted overnight at $4{ }^{\circ} \mathrm{C}$, and clarified, and the sera were aliquotted and frozen at $-80^{\circ} \mathrm{C}$. Antibodies to GST were removed specifically by passage over columns of GST and GST/BL21(DE3) lysate conjugated to Affi-Gel 15 (BioRad, Richmond, CA). Antibodies to the $\mathrm{C}$ terminus were subsequently purified on Ct-fusion protein conjugated to Affi-Gel 15.

Cell transfections. Rat VAChT cDNA was transfected into HeLa cells using the vaccinia-T7 expression system (Fuerst et al., 1986; Blakely et al., 1991). The parent vector pBluescript SKII (Stratagene, La Jolla, CA) was transfected in parallel as a negative control for transporter expression. Briefly, $10 \mathrm{~cm}$ dishes were seeded with HeLa cells $\left(3 \times 10^{6} \mathrm{cell} / \mathrm{plate}\right.$; American Type Tissue Collection, Rockville, MD) $1 \mathrm{~d}$ before transfection. Media were removed, and virus (VTF7-3, 5 pfu/cell) was added to cells in OPTI-MEM (Life Technologies, Gaithersburg, MD) supplemented with $55 \mu \mathrm{M}$ 2-mercaptoethanol for $30 \mathrm{~min}$, followed by the addition of DNA ( $5 \mu \mathrm{g} /$ dish $)$ as a liposome suspension with a $2: 1$ lipid to DNA ratio (v/v) (Life Technologies). Transfected cells were harvested 18 $\mathrm{hr}$ after transfection for immunoblots.

Immunoblot analysis. Western blots were performed as described previously (Ciliax et al., 1995). Briefly, GST, GST/Ct-fusion protein, solubilized membranes ( $10 \%$ SDS at room temperature for $30 \mathrm{~min}$ ) from $\mathrm{HeLa}$ cells transfected with rat VAChT cDNA or pBluescript, and SDS solu-
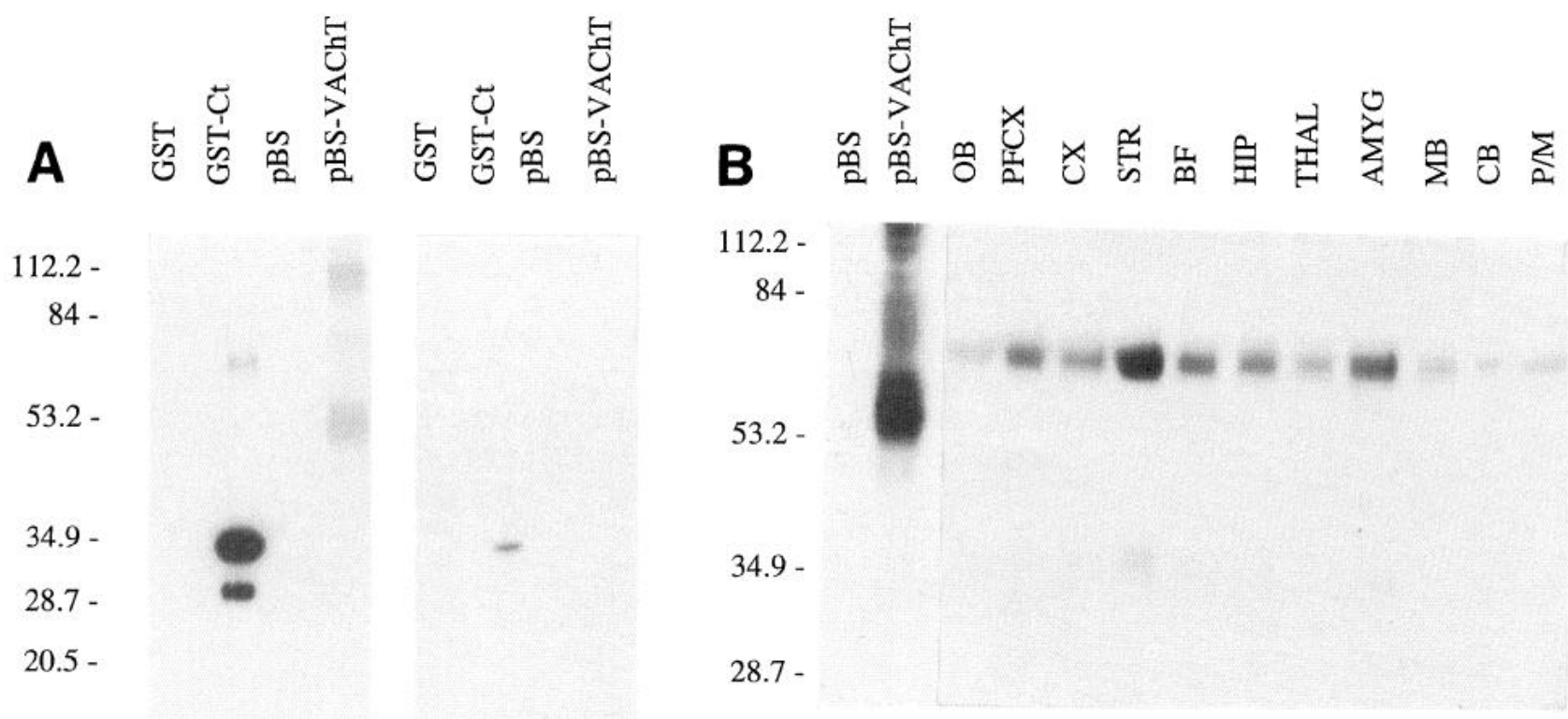

$34.9-$

$28.7-$

\section{Preadsorbed}

Figure 1. Characterization and specificity of VAChT C-terminus antibodies by Western blotting. A, SDS-PAGE was performed on GST (GST, 500 ng), purified C-terminus fusion protein (GST-Ct, $10 \mathrm{ng}$ ), HeLa cells transfected with pBluescript vector only ( $p B S, 10 \mu \mathrm{g})$, and HeLa cells transfected with VAChT cDNA $(p B S-V A C h T, 10 \mu \mathrm{g})$. The blots were probed with affinity-purified C-terminus antibodies $(0.5 \mu \mathrm{g} / \mathrm{ml})$ before $(-)$ or after $(+)$ preadsorption on $100 \mu \mathrm{g}$ of homologous fusion protein conjugated to Affi-Gel 15 and developed for $1 \mathrm{~min}$ as described in Materials and Methods. $B$, HeLa cells transfected with pBluescript $(50 \mu \mathrm{g})$ or VAChT $(50 \mu \mathrm{g})$ and brain homogenates $(100 \mu \mathrm{g} / \mathrm{ml})$, as indicated, and developed for $5 \mathrm{~min}$. Abbreviations: $O B$, olfactory bulb; $P F C X$, prefrontal cortex; $C X$, cortex; STR, striatum; $B F$, basal forebrain; $H I P$, hippocampus; $T H A L$, thalamus; $A M Y G$, amygdala; $M B$, midbrain; $C B$, cerebellum; $P / M$, pons/medulla. 


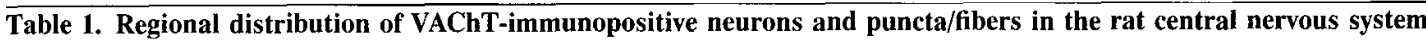

\begin{tabular}{|c|c|c|c|}
\hline & \multicolumn{2}{|c|}{ Relative density of neurons } & \multirow{2}{*}{$\frac{\text { Relative density of puncta/fibers }}{\text { VAChT }}$} \\
\hline & ChAT & VAChT & \\
\hline Olfactory bulb & - & - & ++ \\
\hline \multicolumn{4}{|l|}{ Cerebral cortex } \\
\hline Layer I & - & - & ++ \\
\hline Layers II/III & + & $?$ & + \\
\hline Layer IV & - & - & ++ \\
\hline Layer V & - & - & ++ \\
\hline Layer VI & - & - & + \\
\hline Olfactory cortex & - & - & +++ \\
\hline Olfactory tubercle & + & 1 & ++++ \\
\hline Islands of Calleja & + & + & +++ \\
\hline Bed nucleus of stria terminalis & - & - & + \\
\hline \multicolumn{4}{|l|}{ Basal forebrain } \\
\hline Medial septum & +++ & +++ & ++ \\
\hline Lateral septum & - & - & ++ \\
\hline Vertical/horizontal limb of diagonal band & +++ & +++ & ++ \\
\hline Nucleus basalis of Meynert & +++ & +++ & ++ \\
\hline Striatum & ++ & ++ & $+++1+++$ \\
\hline \multicolumn{4}{|l|}{ Thalamus } \\
\hline Anteroventral & - & - & $+++1++$ \\
\hline Central medial & - & - & ++ \\
\hline Rhomboid & - & - & ++ \\
\hline Mediodorsal lateral & - & - & + \\
\hline Dorsal lateral geniculatc & - & - & ++ \\
\hline Ventral lateral geniculate & - & - & ++ \\
\hline Reticular nucleus & - & - & ++ \\
\hline Zona incerta & - & - & + \\
\hline \multicolumn{4}{|l|}{ Epithalamus } \\
\hline Medial habenula & +++ & +++ & + \\
\hline Lateral habenula & - & - & + \\
\hline Dorsal fornix & - & - & + \\
\hline Fimbria fornix & - & - & + \\
\hline \multicolumn{4}{|l|}{ Hippocampal formation } \\
\hline CA1 & + & - & ++ \\
\hline CA3 & + & - & +++ \\
\hline Dentate gyrus & - & - & ++ \\
\hline \multicolumn{4}{|l|}{ Amygdala } \\
\hline Basolateral nucleus & - & - & $+++t$ \\
\hline Lateral nucleus & - & - & ++ \\
\hline \multicolumn{4}{|l|}{ Superior colliculus } \\
\hline Intermediatc layer & - & - & ++ \\
\hline Periaqueductal gray & - & - & + \\
\hline Red nucleus & - & - & + \\
\hline Interpeduncular nucleus & - & - & ++++ \\
\hline Pedunculopontine and laterodorsal tegmental nucleus & +++ & +++ & + \\
\hline Parabigeminal/lemniscal nucleus & + & + & + \\
\hline Lateral lemniscal nucleus & - & - & ++ \\
\hline Pontine nuclei & - & - & +++ \\
\hline Dorsal raphe & - & - & + \\
\hline Cochlear nucleus & - & - & ++ \\
\hline \multicolumn{4}{|l|}{ Cranial nerves } \\
\hline Oculomotor nucleus & +++ & +++ & + \\
\hline Trochlear nucleus & +++ & $+t+$ & + \\
\hline Motor nucleus of trigeminal & $+t+$ & +++ & $+++^{*}$ \\
\hline Spinal nucleus of trigeminal & - & - & +++ \\
\hline Abducens nucleus & ++ & $+t$ & + \\
\hline Facial motor nucleus & +++ & +++ & $+++^{*}$ \\
\hline Nucleus ambiguous & +++ & +++ & 1 \\
\hline Dorsal motor nucleus of vagus & $++t$ & +++ & ++ \\
\hline \multicolumn{4}{|l|}{ Nucleus of solitary tract } \\
\hline Lateral & - & - & +++ \\
\hline Medial & - & - & +++ \\
\hline Hypoglossal & +++ & ++ & $+++^{*}$ \\
\hline \multicolumn{4}{|l|}{ Spinal cord } \\
\hline Dorsal horn & - & - & ++ \\
\hline Intermediate zone & ++ & $+t$ & ++ \\
\hline
\end{tabular}

VAChT and ChAT immunoreactivity were evaluated on adjacent sections of rat brain processed for immunocytochemistry as described in Materials and Methods. The relative density of immunopositive somata or puncta/fibers was subjectively rated as follows: $(-)$ absent; $(+)$ low; $(++)$ moderate; $(+++)$ high; $(++++)$ very high. In cortex, faintly labeled neurons were observed in some but not all cases and thus are labeled as uncertain (?). In several cranial nerve motor nuclei, large puncta decorated VAChTimmunopositive somata and dendrites, as indicated by an asterisk $\left(^{*}\right)$. 
bilized homogenates of rat brain were fractionated by SDS-PAGE and electroblotted overnight onto polyvinylidene fluoride membrane (Millipore, Bedford, MA). Blots were blocked with $5 \%$ dry milk in $50 \mathrm{~mm}$ Tris buffered saline (TBS), $\mathrm{pH} 7.4$, followed by overnight incubation with primary antibody $(0.5 \mu \mathrm{g} / \mathrm{ml})$ at $4^{\circ} \mathrm{C}$. Membranes were rinsed and incubated for $1 \mathrm{hr}$ with peroxidase-conjugated goat anti-rabbit IgG (BioRad) at room temperature. Immunoreactivity was detected by enhanced chemiluminescence on film (Amersham, Buckinghamshire, UK). For preadsorption experiments, blots were incubated with primary antibody that had been preadsorbed with $100 \mu \mathrm{g}$ of Ct-fusion protein conjugated to Affi-Gel 15 (BioRad) for $1 \mathrm{hr}$ at room temperature.

Immunocytochemistry. Adult male Sprague-Dawley rats $(n=8)$ were given 300 IU of heparin i.p., deeply anesthetized with $4 \%$ chloral hydrate, and transcardially perfused with $0.9 \%$ saline with $0.005 \%$ sodium nitroprusside for $1 \mathrm{~min}, 3 \%$ paraformaldehyde $(200 \mathrm{ml}$ for $10 \mathrm{~min}$ ), and $10 \%$ sucrose $(200 \mathrm{ml}$ for $10 \mathrm{~min})$. Brains were removed and cryoprotected in $30 \%$ sucrose at $4^{\circ} \mathrm{C}$. Fifty micron sections were cut on a freezing-sliding microtome and collected in $50 \mathrm{~mm}$ TBS, pH 7.2. Sections were preblocked in TBS with $4-8 \%$ normal goat serum (NGS), $0.1 \%$ Triton $\mathrm{X}-100$, and avidin $(10 \mu \mathrm{g} / \mathrm{ml})$. Sections were then incubated in rabbit affinity-purified antibody to VAChT $(0.5 \mu \mathrm{g} / \mathrm{ml})$, biotin $(50 \mu \mathrm{g} / \mathrm{ml}), 2 \%$ NGS, and $0.1 \%$ Triton X-100 for $2 \mathrm{~d}$ at $4^{\circ} \mathrm{C}$. Biotinylated goat anti-rabbit IgG secondary was used with $4 \%$ NGS and $0.1 \%$ Triton X-100 for $12 \mathrm{hr}$, and the avidin-biotin-complex method (ABC Elite; Vector, Burlingame, $\mathrm{CA})$ was used to visualize immunoreactivity. Tissue was rinsed between all steps with TBS four times for $10 \mathrm{~min}$ each timc. The peroxidase reaction was developed in $0.05 \%$ diaminobenzidine $(\mathrm{DAB})$ and $0.01 \%$ $\mathrm{H}_{2} \mathrm{O}_{2}$ until a dark brown reaction product was evident. Sections were rinsed several times in TBS, mounted on subbed slides, dehydrated in alcohols, defatted in Histoclear (National Diagnostics, Atlanta, GA), and coverslipped for light microscopic analysis.

Control experiments were run in parallel to confirm specificity. Primary antibody was either omitted or was preadsorbed on the fusion protcin conjugated to Affi-Gel 15 (BioRad) for $1 \mathrm{hr}$ at room temperature. Monoclonal (Levey et al., 1983) and polyclonal (German et al., 1985) antibodies to ChAT were also used for comparison.

The immunocytochemistry procedure described above was modificd as follows for electron microscopic localization of VAChT using immunoperoxidase and immunogold techniques. Glutaraldehyde $(0.1-0.2 \%)$ was added to the fixative, and $40-50 \mu \mathrm{m}$ tissue sections were cut on a Vibratome. Detergent was omitted from blocking and from antibody solutions for immunoperoxidase, which was visualized with DAB as described above. For immunogold, the blocking buffer contained $0.05 \%$ Triton X-100 and 5\% NGS; for secondary, sections were incubated for 12 hr at $4^{\circ} \mathrm{C}$ in $1.4 \mathrm{~nm}$ gold-conjugated $\mathrm{Fab}$ fragments of goat anti-rabbit $\mathrm{IgG}$ at 1:50 (Nanoprobe, Stony Brook, NY). Silver enhancement of gold particles was performed using the HQ Silver kit from Nanoprobe. After it was immunostained, the tissue was postfixed with $1 \%$ osmium tetroxide and embedded in Eponate 12 (Ted Pella, Redding, CA), thin-sectioned at $60 \mathrm{~nm}$ on an ultramicrotome, and counterstained en block with $2 \%$ uranyl acetate (immunoperoxidase) or on grids with 5\% uranyl acetate and Reynolds lead citrate [immunogold (Reynolds, 1963)]. Tissue was analyzed on a Jeol JEM-100C transmission electron microscope (Joel, Peabody, MA).

For double-labeling experiments $(n=4)$, tissue was prepared by a modification of the procedure of Levey et al. (1986), whereby ChAT and VAChT were localized simultaneously. Sections were incubated in a mixture of affinity-purified antibodies to VAChT $(0.1 \mu \mathrm{g} / \mathrm{ml})$ and monoclonal antibody AB8 (Levey et al., 1983) to ChAT (1:200) for 48 hir. A combination of biotinylated goat anti-rabbit antibodies and goat antimouse antibodies preadsorbed on rat brain powder were used as secondary antibodies with $12 \mathrm{hr}$ incubations. Brown VAChT-like immunoreactivity was developed first using the avidin-biotin complex and visualized with $\mathrm{DAB}$ as above. Sections were rinsed thoroughly with TBS and sequentially incubated for $1 \mathrm{hr}$ in mouse peroxidase anti-peroxidase (PAP), goat anti-mouse antibody, and PAP once again (Sternberger and Petrali, 1977). Sections were rinsed three times in $0.01 \mathrm{M}$ sodium phosphate buffer, $\mathrm{pH} 6.6$, and all subsequent steps used this buffer only. Blue ChAT-like immunoreactivity was visualized with $0.01 \%$ benzidine dihydrochloride, $0.025 \%$ sodium nitroferricyanide, and $0.3 \%$ hydrogen peroxide on ice. Controls performed in parallel included the omission of one or both of the primary antibodies to ensure the specificity of each. Sections were rinsed immediately and mounted from phosphate buffer, dried overnight, and rinsed briefly in alcohol before coverslipping.

\section{RESULTS}

\section{Immunoblot analysis}

Affinity-purified antibodies against the $C$ terminus were characterized by Western blotting against GST protein, GST/Ct-fusion protein, and membranes from HeLa cells transfected with pBluescript or rat VAChT cDNA. The antibodies were strongly immunoreactive with the GST/Ct-fusion protein, which migrated at an apparent molecular weight (MW) of $35 \mathrm{kDa}$, although they did not react with GST, indicating that affinity-purified antibodies were specifically reactive with epitopes on the VAChT C-tcrminus portion of the fusion protein (Fig. 1A). When blotted against membrane proteins from HeLa cells transfected with VAChT cDNA, an intense band was detected at 50-55 kDa, with lighter bands at $\sim 70$ and $120 \mathrm{kDa}$. A very faint band was also present at $\sim 35 \mathrm{kDa}$ with longer exposures. No bands were present in the pBluescript vector-transfected cells. Preadsorption of the C-terminus antibody with GST/C terminus fusion protein eliminated all immunoreactive bands (Fig. $1 A$ ).

The regional distribution of VAChT immunoreactivity in the rat brain was investigated by Western blot analysis (Fig. 1B). Broad single bands were present at $\sim 70 \mathrm{kDa}$ in most regions. Striatum and amygdala exhibited the highest levels of immunoreactivity. Olfactory bulb, prefrontal cortex, sensorimotor cortex, septum/basal forebrain, hippocampus, thalamus, midbrain, and pons/medulla exhibited intermediate levels of immunoreactivity. In contrast, very little immunorcactivity was present in cerebcllum, a region with low levels of cholinergic innervation. Additionally, a faint band was present at $\sim 35 \mathrm{kDa}$, but only in those regions with the highest levels of the $70 \mathrm{kDa}$ band. Because the 35 $\mathrm{kDa}$ band was also seen in transfected cells and it is smaller than the predicted MW of the core protein $(56.5 \mathrm{kDa})$, it likely represents a degradation product. Preadsorption of the antibody abolished all immunoreactivity (data not shown).

\section{VAChT immunocytochemistry in rat brain}

VAChT immunoreactivity in rat brain corresponded well to the known distribution of ChAT immunoreactive cells and areas of cholinergic innervation with few exceptions (Table 1; Figs. 2, 3). VAChT-immunoreactive cells were present in the magnocellular basal forebrain complex (Figs. $2 B ; 3 A, E$ ), striatum (Figs. $2 B$; $3 A, D ; 5 A, B$ ), medial habenula (Fig. $2 D$ ), mesopontine tegmental complex (Fig. $2 F$ ), cranial nerve motor nuclei (Figs. $2 G, H ; 6 C, D$ ), and ventral horn and intermediate zone of the spinal cord (see Fig. $6 A, B)$. All immunoreactivity was abolished with preadsorption of the antibody with GST/Ct-fusion protein (Fig. $3 B$ ). The presence of intrinsic cortical neurons was ambiguous; rare, small, and lightly stained neurons were seen occasionally (Fig. $3 C$ ), but they were much less apparent than the bipolar neurons visualized with polyclonal ChAT antibodies. Perikarya and proximal dendrites were filled with $\mathrm{DAB}$ reaction product at sites of VAChT immunoreactivity, whereas nuclear and glial labeling were absent. Within the basal forebrain and striatum, double-labeling experiments confirmed that ChAT and VAChT are coexpressed in these populations of neurons (Fig. $3 F$ ).

VAChT-immunoreactive fibers and varicosities were present in many areas throughout the brain. In neocortex, immunoreactivity was concentrated generally in layers I, IV, and V, whereas layers II, III, and VI contained fewer puncta and fibers (Fig. 3C). Olfactory cortex showed a particularly dense labeling compared with other cortical regions (Fig. $2 B, C$ ). In the hippocampal formation, area CA3 contained more puncta than CA1 did (Fig. 4A). The highest density of puncta and fibers was present within and 

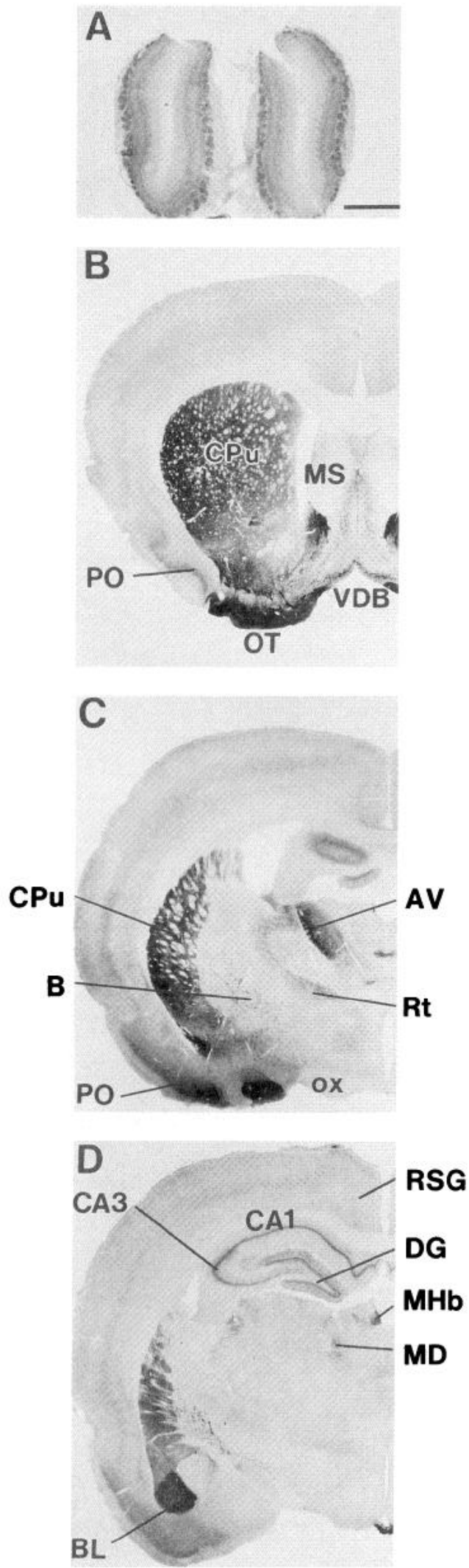
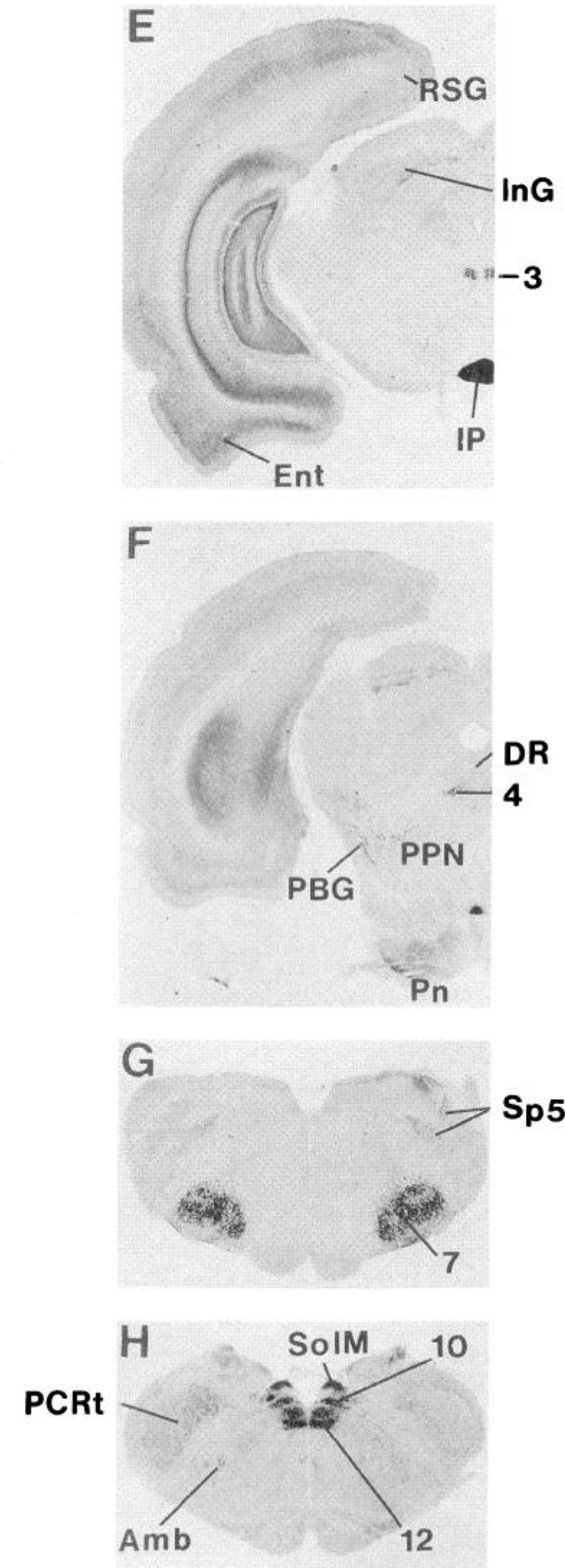

Figure 2. Immunocytochemical distribution of VAChT-immunoreactivity in the rat brain. Representative coronal sections are shown from rostral $(A)$ to caudal $(H)$. Abbreviations: $C P u$, caudate putamen; $M S$, medial septum; $V D B$, vertical limb of diagonal band; $O T$, olfactory tubercle; $P O$, primary olfactory cortex; $B$, nucleus basalis of Meynert; $A V$, anteroventral thalamic nucleus; $R t$, reticular thalamic nucleus; $o x$, optic chiasm; $R S G$, retrosplenial granular cortex; $M H b$, medial habenular nucleus; $M D$, mediodorsal thalamic nucleus; $C A 1, C A 1$ region of hippocampus; $C A 3, \mathrm{CA} 3$ region of hippocampus; $D G$, dentate gyrus; $B L$, basolateral amygdaloid nucleus; Ent, entorhinal cortex; $\operatorname{In} G$, intermediate gray layer of superior colliculus; 3 , oculomotor nucleus; $I P$, interpeduncular nucleus; 4 , trochlear nucleus; $P B g$, parabigeminal nucleus; $P P N$, pedunculopontine nucleus; $D R$, dorsal raphe; $P n$, pontine nuclei; $s p 5$, spinal trigeminal nerve; 7 , facial nucleus; 10 , dorsal motor vagus nucleus; SolM, medial nucleus of solitary tract; 12 , hypoglossal nucleus; PCRt, parvocellular reticular nucleus; $A m b$, ambiguous nucleus. Scale bar, $1000 \mu \mathrm{m}$. immediately surrounding the pyramidal cell layer, although staining was present throughout all layers (Fig. 4B). The dentate gyrus also exhibited a laminar staining pattern, with the greatest density of puncta and fibers being present in the molecular layer just above the granule cell layer (Fig. 4B).

In the olfactory bulb, puncta were relatively dense within the glomeruli and showed a graded pattern of staining within the various cell layers (Fig. $2 A$ ). The olfactory tubercle, islands of Calleja, and striatum contained densely stained neuropil and puncta (Figs. $2 B ; 3 A$ ). There was a marked mediolateral gradient of striatal staining with highest levels laterally in striatum. Puncta were present in all areas of the basal forebrain, admixed with the 


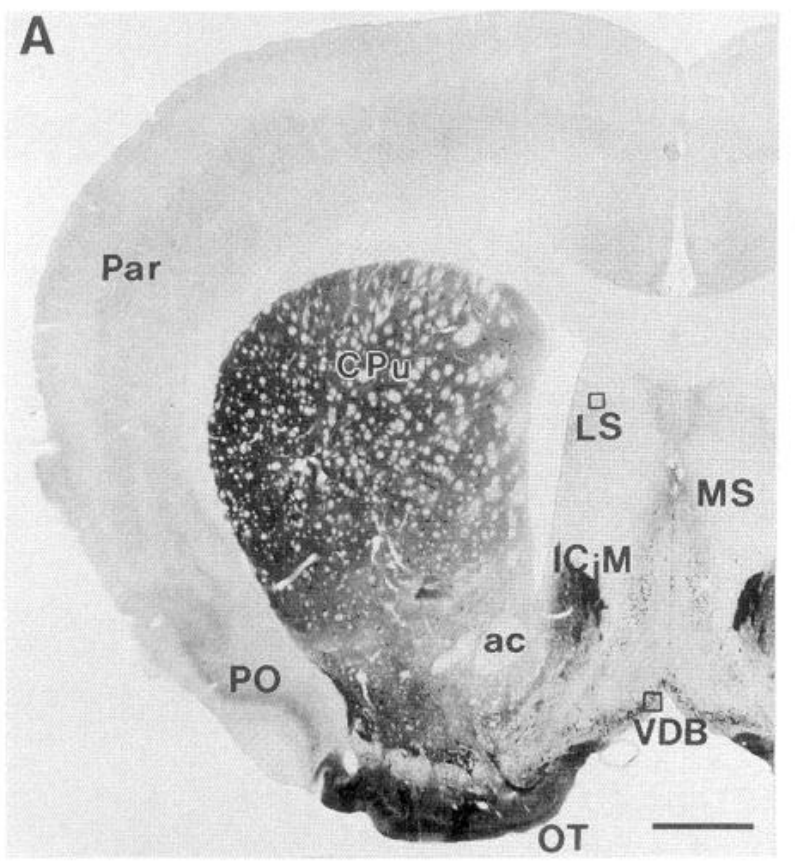

B
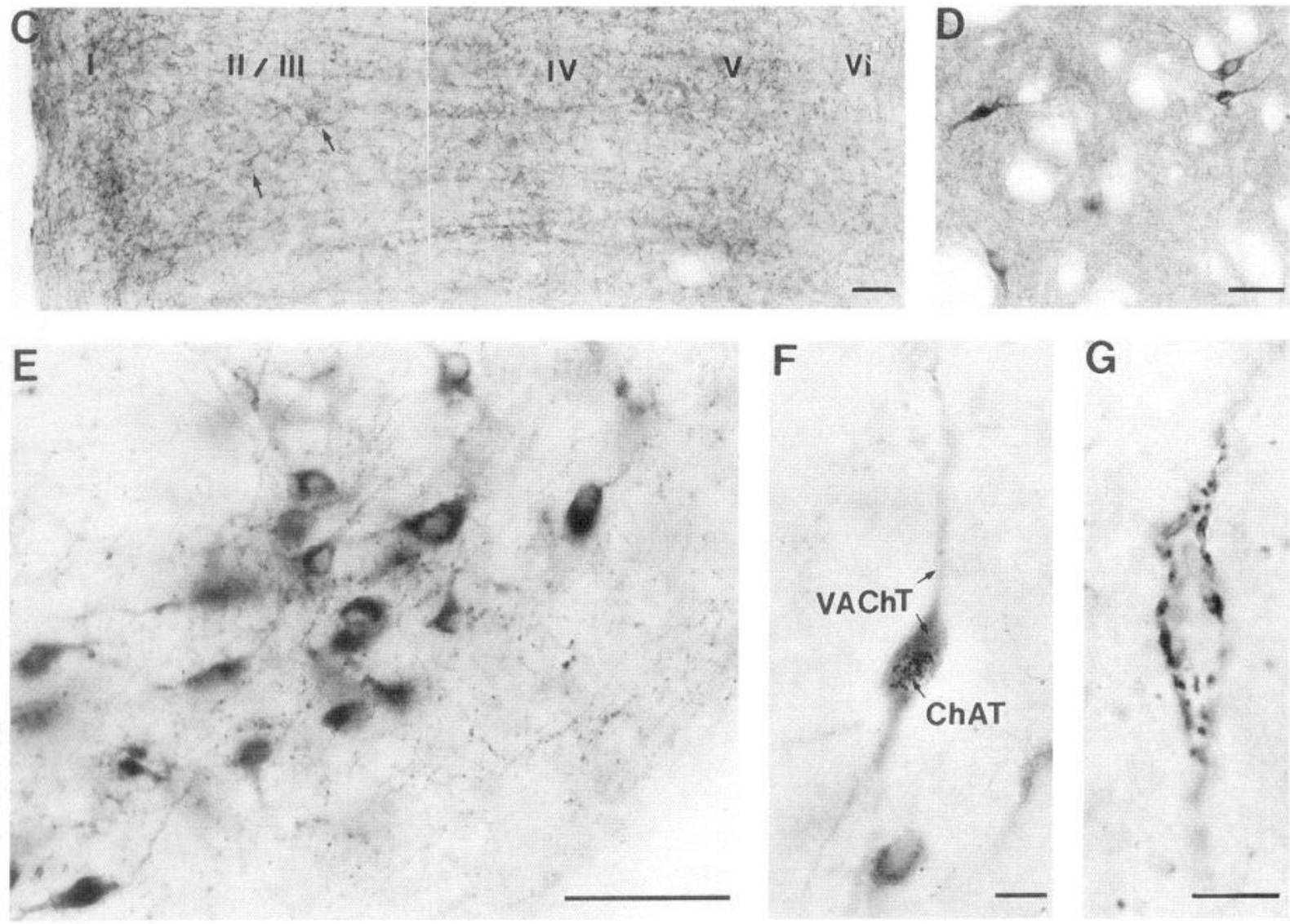

Figure 3. Light microscopic localization of VAChT-immunoreactivity in forebrain. $A$, Coronal section stained with VAChT C-terminus antibodies ( 0.5 $\mu \mathrm{g} / \mathrm{ml})$. Stained cells are present in the medial septum $(M S)$, vertical limb of the diagonal band $(V D B)$, and striatum $(C P u)$. Punctate staining is present throughout the cortex and is particularly dense in the primary olfactory cortex $(P O)$. Dense punctate labeling is also present in the olfactory tubercle $(O T)$, island of Calleja majoris $(I C j M)$, and striatum. Additional abbreviations: Par, parietal cortex; $L S$, lateral septum; $a c$, anterior commissure. $B$, Coronal brain section stained with VAChT C-terminal antibodies preadsorbed on $100 \mu \mathrm{g}$ of C-terminus fusion protein as described in Materials and Methods. $C$, VAChT-like punctate and fiber staining in the somatosensory cortex. Note the heavy labeling in layers I, IV, and V. Arrows indicate possible VAChT-positive intrinsic cortical neurons. $D$, In striatum, dense neuropil staining is evident as are large cells with aspiny dendrites, typical of striatal cholinergic interneurons. $E$, Section of vertical limb of diagonal band is an enlargement of boxed area in $A$. Note the dense puncta in the neuropil surrounding immunoreactive perikarya. $F$, Example of a double-labeled cell in the diagonal band; VAChT-like immunoreactivity is present in the soma and proximal dendrites, and ChAT-immunoreactivity is granular and coexpressed in the soma. G, Enlargement of the boxed area of the lateral septum in $A$. An unlabeled soma and proximal dendrites are outlined by a dense "basket-like" plexus of VAChT-like punctate immunoreactivity. Scale bars: $A$, $B, 1000 \mu \mathrm{m} ; C-E, 50 \mu \mathrm{m} ; F, G, 10 \mu \mathrm{m}$. 
A

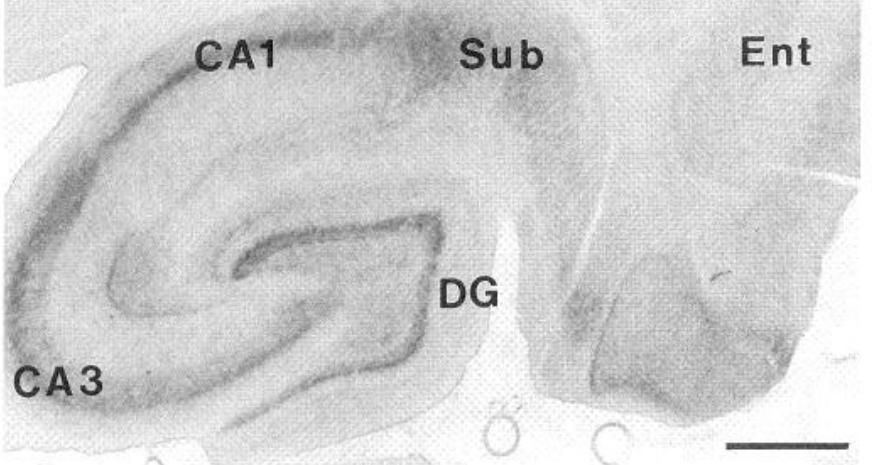

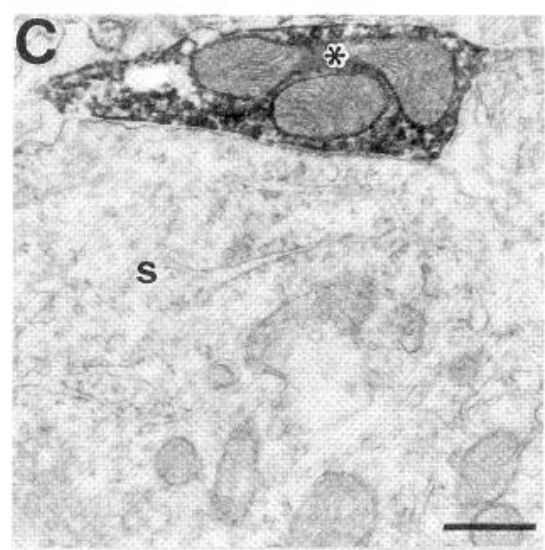

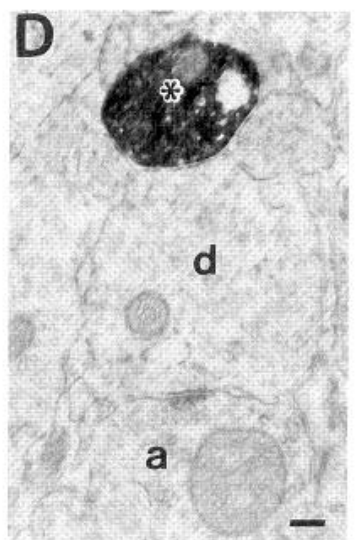

B
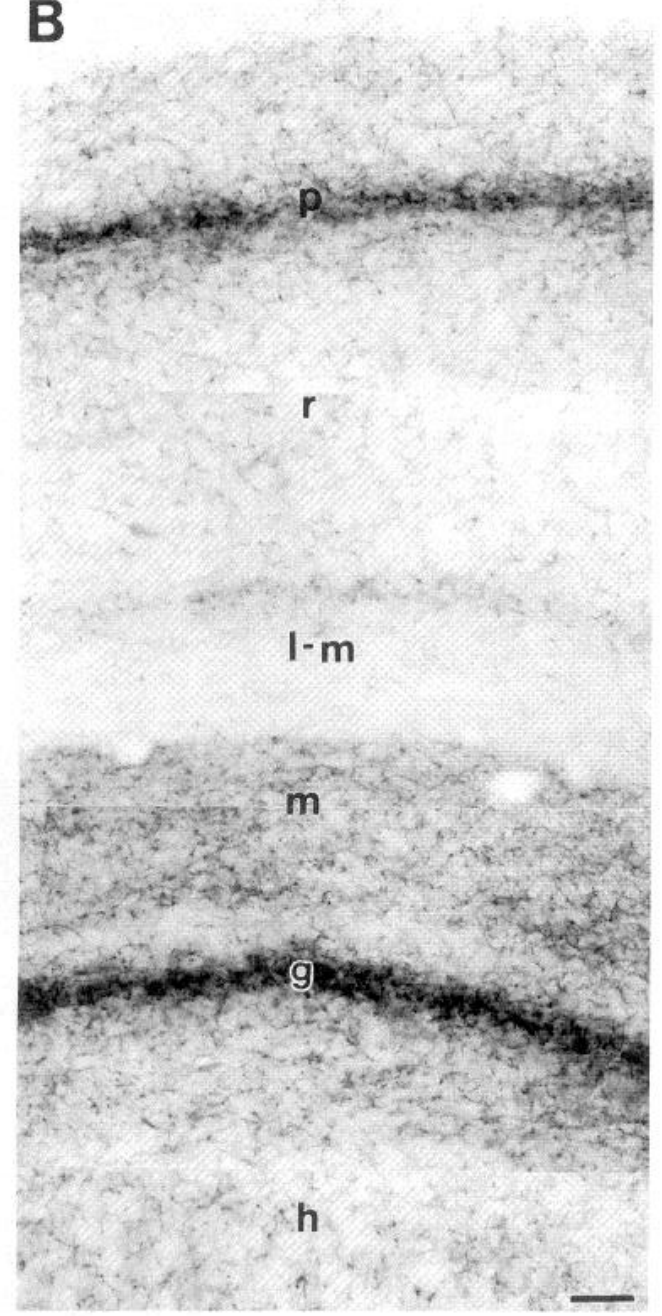

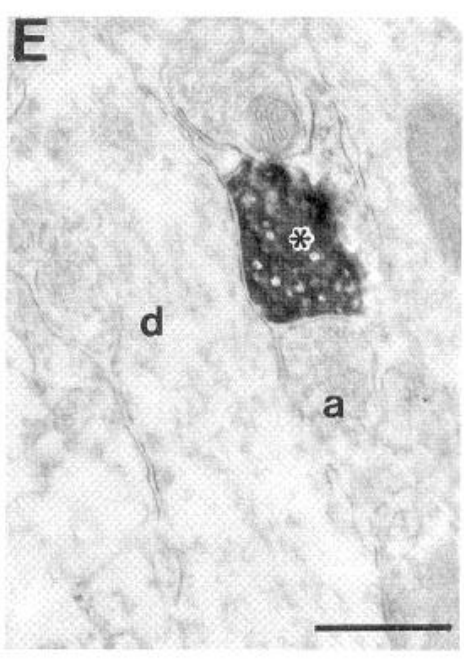

G

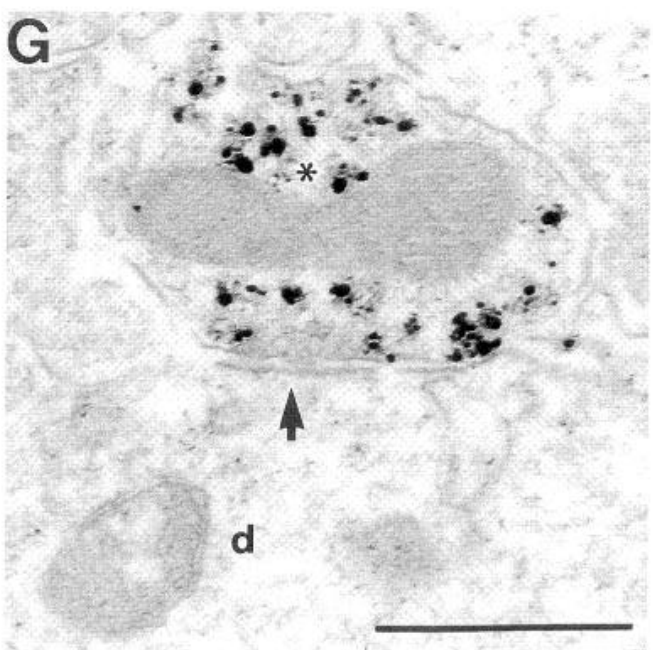

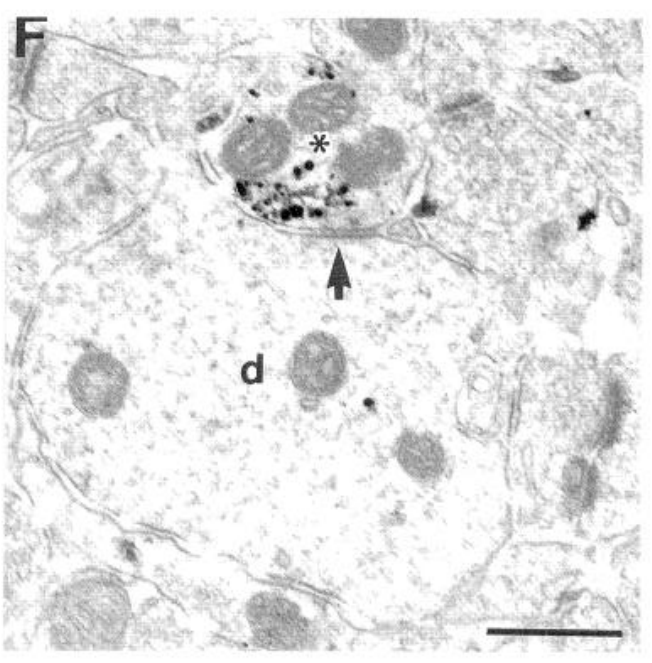

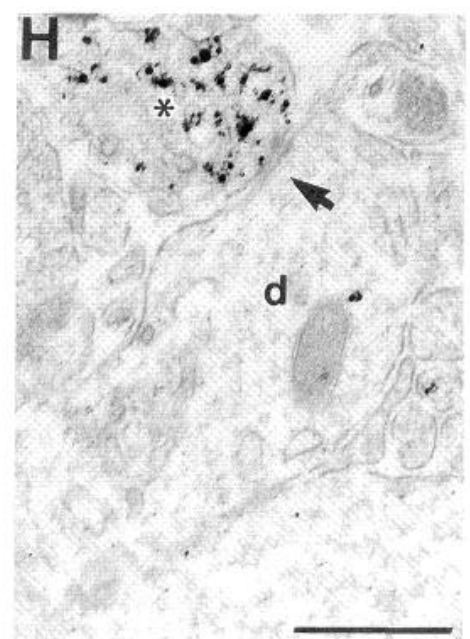

Figure 4. Light and electron microscopic immunocytochemical localization of VAChT in the hippocampal formation. $A$, Low-power micrograph shows the overall staining pattern in the hippocampal formation and entorhinal cortex. Staining is more dense in CA 3 than CA1 and is concentrated around the pyramidal cell layer. There is also dense staining in the subiculum $(S u b)$. In the dentate gyrus, staining is concentrated around the granule cell layer. In the entorhinal cortex (Ent), staining is dense in layers II/III. B, Laminar distribution of VAChT-like immunoreactivity in the hippocampus (CA1) and dentate gyrus. $o$, Stratum oriens; $p$, pyramidal layer; $r$, stratum radiatum; $l-m$, stratum lacunosum-moleculare; $m$, molecular layer; $g$, granule layer; $h r$, hilus. $C$, Electron micrograph of an immunoperoxidase VAChT-positive axon terminal (asterisk) that forms a symmetric synapse on an unlabeled soma ( $s$ ) in the dentate gyrus. The DAB reaction product fills the cytoplasm but is not within vesicles. $D$ and $E$, Electron micrographs of immunoperoxidase VAChT-positive axon terminals (asterisk) contacting dendrites in the dentate gyrus. Unlabeled axon terminals $(a)$ also contact the same dendrites. $F$, Electron micrograph of an immunogold VAChT-positive axon terminal (asterisk) making a symmetrical synapse (arrow) with an unlabeled dendrite $(d)$. Gold particles are associated with synaptic vesicles and the plasma membrane. $G$ and $H$, Electron micrographs of immunogold VAChT-positive axon terminals (asterisk) forming symmetric synapses (arrows) with unlabeled dendrites $(d)$. Scale bars: $A, 500 \mu \mathrm{m} ; B, 50 \mu \mathrm{m} ; C-H, 0.5 \mu \mathrm{m}$. 
immunopositive perikarya (Fig. $3 E$ ). In the lateral septum, unlabeled cells were outlined by VAChT-immunoreactive puncta surrounding the cell bodies and proximal dendrites (Fig. $3 G$ ). Punctate reaction product was widespread in the thalamus, with particularly high levels in the anteroventral, mediodorsal, reticular, and intraldminar nuclei (Fig. 2C,D). In the anteroventral nucleus, reaction product was most dense laterally and progressively less medially.

In the brainstem, there was a widespread distribution of VAChT-immunoreactive puncta. The interpeduncular nucleus was one of the most heavily stained areas in the brain (Fig. $2 E$ ). Varying levels were also found in the superior colliculus, pontine nuclei, red nucleus, cochlear nucleus, and dorsal raphe (Fig. $2 F$ ). All somatic and visceral motor neurons in cranial nerve nuclei displayed VAChT immunoreactivity. Moreover, neurons and proximal dendrites in some of these nuclei, including the trigeminal, facial (see Fig. $6 D$ ), and hypoglossal, as well as the anterior horn of the spinal cord (see Fig. $6 A, B$ ), were covered in a plexus of particularly large, positively stained puncta.

\section{Subcellular localization of VAChT}

Flectron microscopy was performed in the hippocampal formation, striatum, and motor nucleus of the facial nerve to evaluate the subcellular localization of VAChT. In addition to immunoperoxidase, which results in very sensitive but diffuse labeling, immunogold was used to determine more precisely the subcellular localization and topology of the VAChT $\mathrm{C}$ terminus. In the dentate gyrus, VAChT-immunopositive terminals contained dense DAB reaction product, which filled the cytoplasm surrounding synaptic vesicles, and made symmetric contacts with unlabeled somata and dendrites (Fig. 4C,D,E). Most silverintensified immunogold particles in CA3 were localized to synaptic vesicles in labeled terminals (Fig. $4 F, G, H$ ); some immunogold particles contacted the presynaptic density and terminal plasma membrane. The size of the immunogold particles made it difficult to determine on which side of the synaptic vesicle membranc the gold was deposited, but where possible, it appeared on the cytoplasmic side. In the striatum, VAChT-labeled somata conformed cytologically to large aspiny cholinergic interneurons (Fig. $5 B$ ). $D A B$ reaction product was associated mainly with the Golgi and endoplasmic reticulum, and nuclear labeling was not evident. Immunogold particles were present almost exclusively on the cytoplasmic face of the Golgi apparatus (Fig. $5 E$ ). In the neuropil, immunogold-positive VAChT terminals were abundant and made symmetrical synapses with unlabeled dendrites and spines (Fig. $5 C, D)$. In the motor nucleus of the facial nerve, large somata filled with DAB reaction product, concentrated in the Golgi and endoplasmic reticulum, received contacts from VAChT-positive terminals (Fig. 6E). These terminals contained dense DAB reaction product in the cytoplasm (Figs. $6 E, F$ ). Immunogold labeling yielded the same results but with more precise spatial localization; in terminals, the immunogold particles werc associatcd selectively with synaptic vesicles (Fig. $6 G, H$ ); in perikarya, the immunogold particles were clearly localized on the cytoplasmic face of the endoplasmic reticulum (Fig. $6 H$ ); and in dendrites, the immunogold particles were associated primarily with smooth endoplasmic reticulum (data not shown).

\section{DISCUSSION}

In the present study, highly specific antibodies to the rat VAChT were developed that enabled the first direct characterization of the encoded protein in rat brain. There were several major find- ings. First, the native protein has a MW of $\sim 70 \mathrm{kDa}$. Second, the protein is expressed selectively in all known cholinergic neurons; the use of double-labeling techniques confirms that ChAT and VAChT, which share a unique genetic arrangement, are colocalized at the protein level. Third, VAChT is localized to the synaptic vesicles of cholinergic axon terminals in the mammalian brain, demonstrating the morphological substrate of its suggested role as a vesicular transporter of ACh. Fourth, ultrastructural microscopic analysis using immunogold shows that VAChT is synthesized in the endoplasmic reticulum and Golgi apparatus with the $\mathrm{C}$ terminus in the cytoplasm; the same orientation is present in synaptic vesicles where discernible. This is consistent with topological models.

\section{Antibody specificity}

The $\mathrm{C}$ terminus of the putative VAChT protein was chosen as a target epitope for antibody production because of its unique and divergent sequence from other vesicular transporter family members, as well as the predicted hydrophilicity and immunogenicity of this region. Several lines of evidence confirm the specificity of the antibodies. First, the antibodies recognized the purified C-teminus fusion protein but not fusion proteins containing the $\mathrm{N}$-terminus and loop regions (data not shown) or purified GST. Second, recognition of the full-length and mature forms of VAChT protein was demonstrated with Western blots of HeLa cells transfected with the rat VAChT cDNA and in rat brain. The dense 55-kDa band present in VAChT-transfected HeLa cells likely represents the core protein, predicted to have a MW of 56.5 $\mathrm{kDa}$ on the basis of the cDNA sequence (Bejanin et al., 1994; Erickson et al., 1994; Roghani et al., 1994). The 70-kDa band present both in VAChT-transfected HeLa cells and in rat brain homogenates is possibly a mature, glycosylated form of the VAChT protein, because two $\mathrm{N}$-linked glycosylation sites are present on the large intravesicular loop (Bejanin et al., 1994; Erickson et al., 1994; Roghani et al., 1994). The protein is enriched in brain areas known to receive dense cholinergic innervation, such as striatum, hippocampus, and amygdala, with the lowest levels in cerebellum where there is little cholinergic input. Finally, the immunohistochemical data also strongly support the specificity of these polyclonal VAChT antibodies. The pattern of VAChT-immunoreactive neurons closely matches the distribution of VAChT mRNA, ChAT mRNA, and ChAT-immunoreactive perikarya, with the few mismatches only in areas where the existence of cholinergic cells is controversial (discussed below). The distribution of VAChT-immunoreactive fibers and their ultrastructural morphology also corresponds with that expected of cholinergic innervation. Thus, there is no doubt that the antibodies are highly specific for the VAChT protcin.

\section{Selective expression in cholinergic neurons}

VAChT immunoreactivity was concentrated in cell groups defined previously as cholinergic by ChAT immunoreactivity and was also present in terminals and fibers of areas of known cholinergic innervation. VAChT-positive cells were present in all cholinergic nuclei of the basal forebrain (Ch1-Ch4), including the medial septal nuclens, the vertical and horizontal limbs of the diagonal band of Broca, and the nucleus basalis of Meynert. The pedunculopontine nucleus (Ch5), laterodorsal tegmental nucleus (Ch6), medial habenula ( $\mathrm{Ch} 7)$, parabigeminal nucleus ( $\mathrm{Ch} 8$ ), and cranial and spinal motor nuclei also contained labeled cells. The colocalization of ChAT and VAChT proteins in double-labeling experiments supports the idea of coregulation of these genes at their 

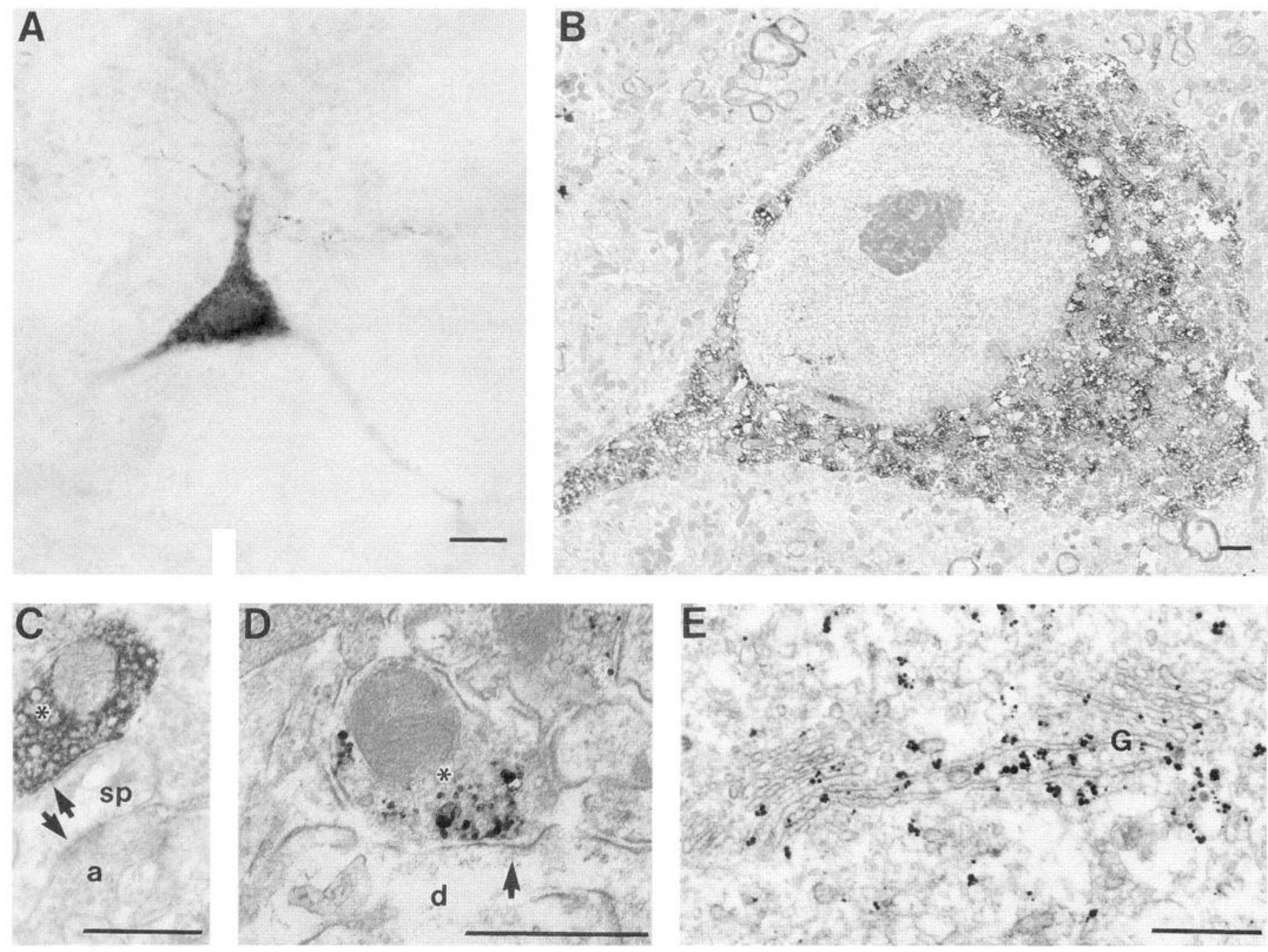

Figure 5. Light and electron microscopic localization of VAChT-immunoreactivity in the striatum. $A$, Light micrograph of a VAChT-positive neuron in the striatum. The soma and proximal dendrites are labeled and the size, indented nucleus, and cytology of the neuron are characteristic of cholinergic interneurons. $B$, Electron micrograph of an immunoperoxidase VAChT-positive neuron. Note the oval shape and abundant cytoplasm filled with organelles, which is typical of cholinergic interneurons. $C$, Electron micrograph of an immunoperoxidase VAChT-positive axon terminal (asterisk) synapsing (arrow) with a dendritic spine $(s p)$. This spine also receives synaptic contact (arrow) from an unlabeled axon terminal (a). $D$, Electron micrograph of an immunogold VAChT-positive axon terminal (asterisk) making a symmetrical synapse (arrow) with an unlabeled dendrite (d). The immunogold is associated with the synaptic vesicles that are clustered at the synaptic active zone. Note also the absence of labeling of the mitochondria. $E$, Electron micrograph of immunogold VAChT-labeling associated with the Golgi complex $(G)$. The immunogold particles are located on the cytoplasmic face of the Golgi membranes, consistent with the VAChT C terminus being cytoplasmic. Scale bars: $A, 10 \mu \mathrm{m} ; B, 1 \mu \mathrm{m} ; C-E, 0.5 \mu \mathrm{m}$.

shared locus. Indeed, the VAChT gene lies within the first intron of the ChAT gene in all species studied to date. Moreover, the mRNAs and both encoded proteins, as shown here, are expressed uniquely in cholinergic neurons, providing more evidence that this genetic locus may be a regulon (Usdin et al., 1995). VAChT mRNA species have been detected with the $5^{\prime}$ exon R, originally found in ChAT mRNA, suggesting that some VAChT and ChAT transcripts may have their expression regulated by a common mechanism. Testing of this hypothesis and further study of the regulation of these genes will now be possible at the protein level using specific antibodies.

The presence of cortical cholinergic neurons has been particularly controversial. ChAT-immunoreactive cortical bipolar neurons have been observed in rodents, but not in primates, with several different antibodies (Cozzari and Hartman, 1980; Eckenstein and Thoenen, 1982; Houser et al., 1983; Levey et al., 1984; German et al., 1985; Houser et al., 1985); however, in situ hybrid- ization to ChAT mRNA has generally not detected positive intrinsic cortical neurons (Butcher et al., 1992, 1993; Oh et al., 1992), with the only exception being in piriform cortex (Ibanez et al., 1991). The cloning of the VAChT gene has provided the opportunity to look at this issue from a new angle. Unfortunately, the results are again ambiguous. Northern blot analysis and PCR experiments show weak signals for VAChT mRNA in cortex and hippocampus (Erickson et al., 1994; Roghani et al., 1994). In situ hybridization studies to VAChT mRNA indicate the presence of VAChT-positive neurons in layers II and III of frontal, parietal, piriform, and occipital cortex but not in hippocampus (Schafer et al., 1994). In the present immunohistochemical study, small neuronal soma are present in layers II and III of cortex, but they are lightly labeled and thus are difficult to identify definitely as positive (Fig. $3 C$ ). VAChT protein may be present in very low levels in the soma of cortical neurons, perhaps being rapidly transported to terminals. More sensitive detection methods may be necessary 

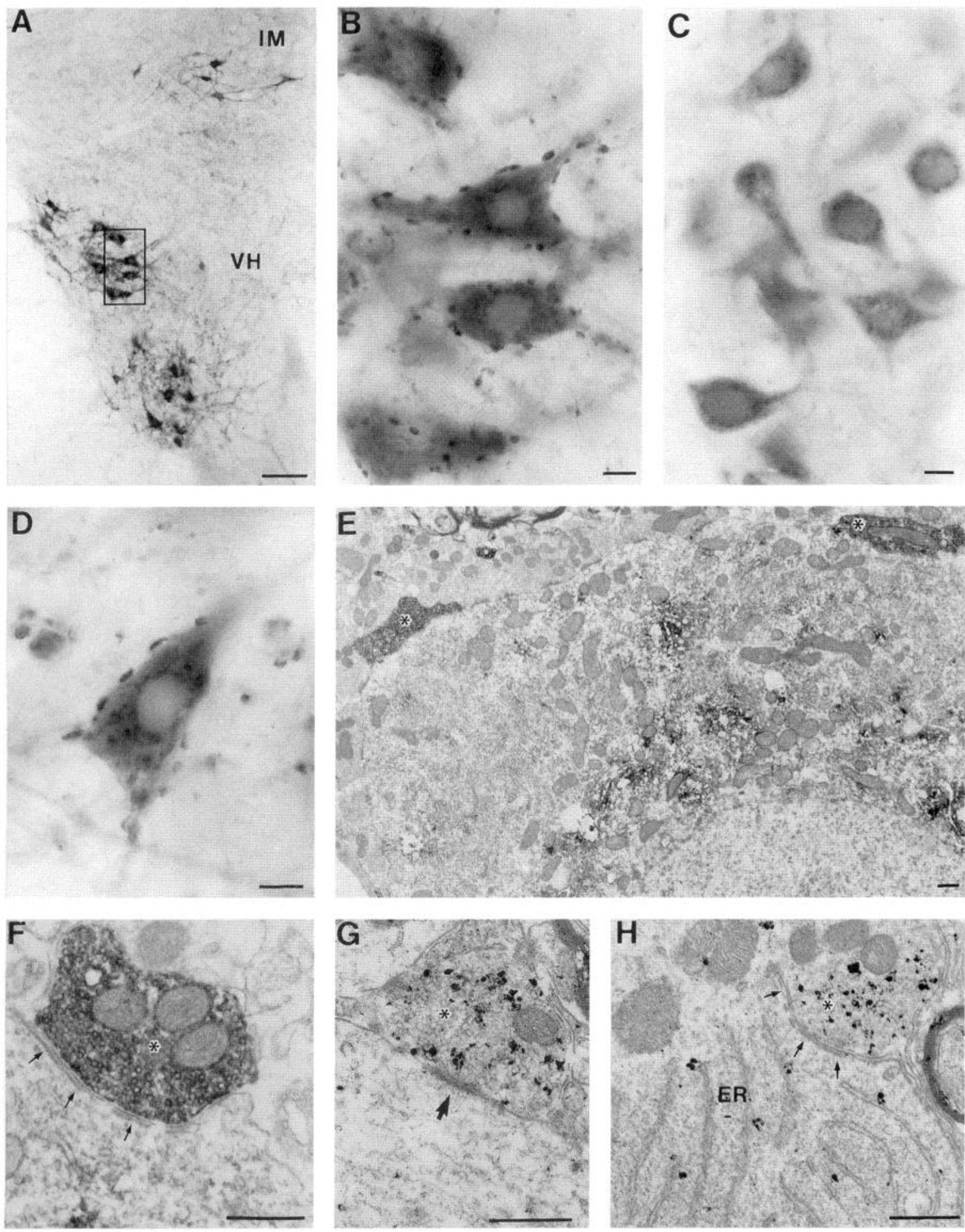

Figure 6. Light and electron microscopic localization of VAChT-immunoreactivity in motor neurons in the brainstem and spinal cord. $A$, Light micrograph of the ventral horn $(V H)$ of the spinal cord and intermediate zone $(I M)$ near the central canal. VAChT-immunopositive motor neurons in the ventral horn are large, typical of $\alpha$ motor neurons, and are covered with labeled puncta. VAChT-immunopositive neurons in the intermediate zone are smaller, with few if any puncta. $B$, Higher magnification of spinal ventral horn neurons boxed in $A$. Note the large, labeled puncta that decorate the labeled soma and proximal dendrites. $C$, VAChT-positive neurons in the oculomotor nucleus. Note the absence of boutons on the cell bodies. $D$, A VAChT-positive neuron in the facial motor nucleus. Large puncta are present on the soma and proximal dendrites. E, Electron micrograph of immunoperoxidase VAChT-positive axon terminals (asterisk) contacting a VAChT-positive neuron in the facial motor nucleus. $F$, Electron micrograph of an immunoperoxidase VAChT-positive terminal (asterisk) contacting a VAChT-positive perikaryon. Subsurface cisterns (arrows), flattened, sheet-like endoplasmic reticulum closely apposed to the soma plasma membrane, are indicative of C-terminal synapses. $G$, Electron micrograph of an immunogold VAChT-positive axon terminal (asterisk) forming a symmetrical synapse (arrowhead) with an immunoreactive soma. The immunogold particles are associated with synaptic vesicles. $H$, Electron micrograph of an immunogold VAChT-positive axon terminal (asterisk) synapsing with an immunoreactive soma. The immunogold particles are associated with synaptic vesicles in the terminal and are on the cytoplasmic face of the endoplasmic reticulum (ER) membranes in the labeled cell. Subsurface cisterns are also present (arrows). Scale bars: $A, 100 \mu \mathrm{m} ; B-D, 10 \mu \mathrm{m} ; E-H, 0.5 \mu \mathrm{m}$. 
to visualize VAChT in somata, as was necessary for the visualization of ChAT (Levey et al., 1984). It is also possible that the presence of VAChT mRNA is not reflected in actual levels of protein produced and used. Because five VAChT mRNAs have been identified to date (Cervini et al., 1995), it is possible that the mRNA produced in cortical neurons does not lead to a mature, detectable VAChT protein.

Many regions of brain, including cerebral cortex, hippocampus, basal forebrain, thalamus, brainstem nuclei, cranial nerve motor nuclei, and spinal cord regions show varying degrees of cholinergic innervation as determined by VAChT immunohistochemistry. Cortical and hippocampal staining patterns match ChAT-immunoreactive fibers and terminals (Houser et al., 1983; Frotscher and Leranth, 1985; Houser et al., 1985; Matthews ct al., 1987), although the VAChT antibodics described here seem to result in more sensitive visualization of cholinergic terminals than most ChAT antibodies. For instance, in the basal forebrain, we found a surprisingly extensive degree of VAChT fibers and terminals. Cholinergic projections to the basal forebrain may arise from local collaterals of the magnocellular ChAT-immunoreactive neurons, or possibly from the mesopontine tegmental complex (Hallanger and Wainer, 1988). The muscarinic effects of acetylcholine released from these terminals is believed to modulate septohippocampal activity and memory processing (Givens and Olton, 1990; Pang et al., 1993). VAChT-positive terminals were also much more prominent than realized previously in the lateral septum. These cholinergic afferents presumably originate in the mesopontine tegmental complex and are believed to modulate REM sleep. Anatomical studies have demonstrated projections from the pedunculopontine nucleus to the lateral septum (Hallanger and Wainer, 1988), and carbachol injections to the pedunculopontine tegmental nucleus immediately elicit hippocampal theta rhythms (Vertes et al., 1993). The presence of baskets of VAChT-immunopositive puncta surrounding lateral septal cells underscores the importance of cholinergic modulation of these neurons. Additionally, we have confirmed the cholinergic nature of the previously defined $\mathrm{C}$ terminals ( $\mathrm{C}$ for cisterns) on motor neurons in the brainstem and spinal cord (Connaughton et al., 1986; Nagy et al., 1993; Li et al., 1995). Although these boutons are among the largest in the CNS, little is known of their origin or physiology.

\section{Ultrastructural localization}

Immunogold electron microscopy demonstrated VAChT localization to synaptic vesicles in several regions with dense cholinergic innervation. The immunogold particles were almost exclusively associated with the small, clear synaptic vesicles in axon terminals that made symmetric contacts with dendrites and perikarya in the areas examined. This is the first direct evidence that the putative VAChT protein is indeed associated with synaptic vesicles in characteristic cholinergic terminals. Immunogold particles were also found in association with the presynaptic density and terminal plasma membrane, presumably through fusion of synaptic vesicles with the plasma membrane. Within labeled perikarya, the immunogold particles were associated with the Golgi apparatus and endoplasmic reticulum, as expected for a membrane-bound protein.

\section{Topology}

The topological models of the VAChT protein, like the other vesicular transporter family members, have been based primarily on two factors. First, hydropathy analysis has been used to predict the 12-transmembrane structure. Second, the location of phosphorylation and glycosylation consensus sequences have suggested that both termini are in the cytoplasm and that the predicted loop between transmembrane domains I and II resides within the vesicular lumen; however, there has been no direct support of these models until now. Both immunoperoxidase and immunogold electron microscopy support the $\mathrm{C}$ terminus being located in the cytoplasm. DAB reaction product was found in the cytoplasm, not intravesicularly. Immunogold particles were localized on the cytoplasmic face of the endoplasmic reticulum and Golgi apparatus and on synaptic vesicles where discernible. Additional topological assessment requires the development of antibodies to epitopes on the $\mathrm{N}$ terminus or intravesicular loop and biochemical analysis.

In conclusion, antifusion protein antibodies were developed and used to demonstrate that the VAChT protein is an excellent and highly specific marker of cholinergic neurons, fibers, and terminals. Immunoblotting and immunohistochemistry localized VAChT in brain regions known or suspected to contain cholinergic cells and terminals. Electron microscopy supports VAChT as an integral membrane synaptic vesicle protein with the $C$ terminus in the cytoplasm. These antibodies will be useful for studies of the regulation of the shared ChAT and VAChT genetic locus, not only in normal tissue but also in pathological conditions such as Alzheimer's disease.

\section{REFERENCES}

Alfonso A, Grundahl K, Duerr JS, Han H-P, Rand JB (1993) The Caenorhabditis elegans unc- 17 gene: a putative vesicular acetylcholine transporter. Science 261:617-619.

Alfonso A, Grundahl K, McManus JR, Asbury JM, Rand JB (1994) Alternative splicing leads to two cholinergic proteins in Caenorhabditis elegarts. J Mol Biol 241:627-630.

Bejanin S, Cervini R, Mallet J, Berrard S (1994) A unique gene organization for two cholinergic markers, choline acetyltransferase and a putative vesicular transporter of acetylcholine. J Biol Chem 269:21944-21947.

Blakely RD, Clark JA, Rudnick G, Amara SG (1991) Vaccinia-T7 RNA polymerase expression system: evaluation for the expression cloning of plasma membrane transporters. Anal Biochem 194:302-308.

Butcher LL, Oh JD, Woolf NJ (1993) Cholinergic neurons identified by in situ hybridization histochemistry. Prog Brain Res 98:1-8.

Butcher LL, Oh JD, Woolf NJ, Edwards RH, Roghani A (1992) Organization of central cholinergic neurons revealed by combined in situ hybridization histochemistry and choline-O-acetyltransferase immunocytochemistry. Neurochem Int 21:429-445.

Cervini R, Houhou L, Pradat P-F, Bejanin S, Mallet J, Berrard S (1995) Specific vesicular acetylcholine transporter promoters lie within the first intron of the rat choline acetyltransferase gene. J Biol Chem 270:24654-24657.

Ciliax BJ, Heilman CJ, Edmunds SM, Hersch SM, Levey AI (1995) Anti-fusion protein antibodies specific for receptor subtypes. In: Receptor molecular biology (Sealfon SC, ed), Methods in neurosciences, Vol 25 (Conn PM, ed) pp 431-454. Orlando: Academic.

Connaughton M, Priestley JV, Sofroniew MV, Eckenstein F, Cuello AC (1986) Inputs to motorneurones in the hypoglossal nucleus of the rat: light and electron microscopic immunocytochemistry for choline acetyltransferase, substance $\mathrm{P}$ and enkephalins using monoclonal antibodies. Neuroscience 17:205-224.

Coyle JT, Price DL, DeLong MR (1983) Alzheimer's disease: a disorder of cortical cholinergic imnervation. Science 219:1184-1190.

Cozzari C, Hartman BK (1980) Preparation of antibodies specific to choline acetyltransferase from bovine caudate nucleus and immunohistochemical localization of the enzyme. Proc Natl Acad Sci USA 77:7453-7457.

Eckenstein F, Thoenen $H$ (1982) Production of specific antisera and monoclonal antibodies to choline acetyltransferase: characterization and use for identification of cholinergic neurons. EMBO J 1:363-368. 
Erickson JD, Varoqui H, Schafer MK-H, Modi W, Diebler M-F, Weihe E, Rand J, Eiden LE, Bonner TI, Usdin TB (1994) Functional identification of a vesicular acetylcholine transporter and its expression from a "cholinergic" gene locus. J Biol Chem 269:21929-21932.

Frotscher M, Leranth C (1985) Cholinergic innervation of the rat hippocampus as revealed by choline acetyltransferase immunocytochemistry: a combined light and electron microscopic study. J Comp Neurol 239:237-246.

Fucrst TS, Nilcs EG, Studicr FW, Moss B (1986) Eukaryotic transientexpression system based on recombinant vaccinia virus that synthesizes bacteriophage T7 RNA polymerase. Proc Natl Acad Sci USA $83: 8122-8126$.

German DC, Bruce G, Hersh LB (1985) Immunohistochemical staining of cholinergic neurons in the human brain using a polyclonal antibody to choline acetyltransferase. Neurosci Lett 61:1-5.

Givens BS, Olton DS (1990) Cholinergic and GABAergic modulation of medial septal area: effect on working memory. Behav Neurosci 104:849-855.

Hallanger AE, Wainer BH (1988) Ascending projections from the pedunculopontine tegmental nucleus and the adjacent mesopontine tegmentum in the rat. J Comp Neurol 274:483-515.

Houser CR, Crawford GD, Barber RP, Salvaterra PM, Vaughn JE (1983) Organization and morphological characteristics of cholinergic neurons: an immunohistochemical study with monoclonal antibody to choline acetyltransferase. Brain Res 266:97-119.

Houser CR, Crawford GD, Salvaterra PM, Vaughn JE (1985) Immunocytochemical localization of choline acetyltransferase in rat cerebral cortex: a study of cholinergic neurons and synapses. J Comp Neurol 234:17-34.

Ibanez CF, Ernfors P, Persson H (1991) Developmental and regional expression of choline acetyltransferase $\mathrm{mRNA}$ in the rat central nervous system. J Neurosci Res 29:163-171.

Kish SJ, Distefano LM, Dozic S, Robitaille Y, Rajput A, Deck JHN, Hornykiewicz O (1990) $\left[{ }^{3} \mathrm{H}\right]$ Vesamicol binding in human brain cholinergic deficiency disorders. Neurosci Lett 117:347-352.

Levey AI, Armstrong DM, Atweh SF, Terry RD, Wainer BH (1983) Monoclonal antibodics to cholinc acctyltransfcrasc: production, specificity, and immunohistochemistry. J Neurosci 3:1-9.

Levey AI, Bolam JP, Rye DB, Hallanger AE, Demuth RM, Mesulam M-M, Wainer BH (1986) A light and electron microscopic procedure for sequential double antigen localization using diaminobenzidine and benzidine dihydrochloride. J Histochem Cytochem 34:1449-1457.

Levey AI, Wainer BH, Rye DB, Mufson EJ, Mesulam M-M (1984) Choline acetyltransferase-immunoreactive neurons intrinsic to rodent cortex and distinction from acetylcholinesterase-positive neurons. Neuroscience 13:341-353.
Li W, Ochalski PA, Brimijoin S, Jordan LM, Nagy JI (1995) C-terminals on motorneurons: electron microscope localization of cholinergic markers in adult rats and antibody-induced depletion in neonates. Neuroscience 65:879-891.

Matthews DA, Salvaterra PM, Crawford GD, Houser CR, Vaughn JE (1987) An immunocytochemical studly of choline acetyliransferase containing neurons and axon terminals in normal and partially deafferented hippocampal formation. Brain Res 402:30-43.

Nagy JI, Yamamoto T, Jordan LM (1993) Evidence for the cholinergic nature of $\mathrm{C}$-terminals associated with subsurface cisterns in alphamotorneurons of rat. Synapse 15:17-32.

Oh JD, Woolf NJ, Roghani A, Edwards RH, Butcher LL (1992) Cholinergic neurons in the rat central nervous system demonstrated by in situ hybridization of choline acetyltransferase mRNA. Neuroscience 47:807-822.

Pang K, Williams MJ, Olton DS (1993) Activation of the medial septal area attenuates LTP of the lateral perforant path and enhances heterosynaptic LTD of the medial perforant path in aged rats. Brain Res 632:150-160.

Reynolds $\mathrm{E}$ (1963) The use of lead citrate at high $\mathrm{pH}$ as an electron opaque stain in electron microscopy. J Cell Biol 117:208-212.

Roghani A, Feldman J, Kohan S, Shirzadi A, Gunderson CB, Brecha N, Edwards RH (1994) Molecular cloning of a putative vesicular transporter for acetylcholine. Proc Natl Acad Sci USA 91:10620-10624.

Ruberg M, Mayo W, Brice A, Duyckaerts C, Hauw JJ, Simon H, LeMoal M, Agid Y (1990) Choline acetyltransferase activity and $\left[{ }^{3} \mathrm{H}\right]$ vesamicol binding in the temporal cortex of patients with Alzheimer's disease, Parkinson's discase, and rats with basal forcbrain lesions. Neuroscience 35:327-333.

Schafer MK-II, Wcihe E, Varoqui II, Eiden LE, Erickson JD (1994) Distribution of the vesicular acetylcholine transporter (VAChT) in the central and peripheral nervous systems of the rat. J Mol Neurosci $5: 1-26$.

Smith DB, Johnson KS (1988) Single-step purification of polypeptides expressed in Escherichia coli as fusions with glutathione S-transferase. Gene 67:31-40.

Sternberger LA, Petrali JP (1977) The unlabeled antibody enzyme method. Attemptcd usc of pcroxidasc-conjugatcd antigen as the third layer in the technique. J Histochem Cytochem 25:1036-1042.

Usdin TB, Eiden LE, Bonner TI, Erickson JD (1995) Molecular biology of the vesicular ACh transporter. Trends Neurosci 18:218-224.

Vertes RP, Colom LV, Fortin WJ, Bland BH (1993) Brainstem sites for the carbachol elicitation of the hippocampal theta rhythm in the rat. Exp Brain Res 96:419-429. 